\title{
64. Seminar biljne zaštite - seminar iz varstva rastlin v Opatiji
}

\author{
Andreja KAVČIČ ${ }^{*}$, Nina ŠRAMEL ${ }^{1}$
}

\section{Uvod}

Vsako leto v začetku februarja Hrvaško društvo za varstvo rastlin (Hrvatsko društvo biljne zaštite, https://hdbz.hr/) organizira Seminar varstva rastlin (Seminar biljne zaštite) v Opatiji. Letošnji, že 64. po vrsti, je potekal od 4. do 7. februarja. Rdeča nit tokratnega seminarja je bilo Mednarodno leto varstva rastlin 2020. Zvrstilo se je veliko predavanj na omenjeno temo, tako v sekciji za gozdarstvo kot v sekciji za kmetijstvo. Temu primeren je bil tudi izbor vabljenih predavateljev.

\section{Mednarodno leto zdravja rastlin 2020}

Seminar je svečano otvoril predsednik upravnega odbora Mednarodnega leta zdravja rastlin 2020 Ralf Lopian. Predstavil je ozadje in pomen Mednarodnega leta zdravja rastlin (https://www.ippc.int/en/iyph/), ter pomen osveščanja javnosti za izboljšanje in ohranjanje zdravstvenega stanja rastlin in $\mathrm{s}$ tem zdravja celega planeta. Poudaril je, da sta zgodnje zaznavanje in hitro ukrepanje proti škodljivim organizmom ključna za zdravje rastlin in da lahko vsak posameznik naredi veliko že $s$ tem, da osvešča okolico o pomenu zdravih rastlin za planet in daje zgled $\mathrm{z}$ aktivnim prizadevanjem in vključevanjem v aktivnosti na tem področju. Predstavnik Evropske komisije, Direktorata za zdravje in varnost hrane (DG SANTE, https://ec.europa.eu/info/departments/health-and-food-safety en) Roman Vagner, je predstavil novo zakonodajo na področju zdravja rastlin, t. i. Uredbo (EU) 2016/2031 Evropskega parlamenta in Sveta o ukrepih varstva pred škodljivimi organizmi rastlin (https://eur-lex.europa.eu/legal-content/s1/TXT/?uri=CELEX\%3A32016R2031). V zvezi z novo zakonodajo bo Evropska komisija v letih 2020-2021 organizirala sklop izobraževanj oz. delavnic BTSF (Better Training for Safer Food). Prav tako bo na Finskem od 5. do 8. oktobra 2020 organizirana mednarodna konferenca o zdravju rastlin (http://www.fao.org/plant-health-2020/events/events-

detail/en/c/1250609/). Predstavnik sekretariata mednarodne konvencije za varstvo rastlin (International Plant Protection Convention, IPPC) Mirko Montuori je predstavil številne aktivnosti, ki bodo v sklopu Mednarodnega leta zdravja rastlin potekale po Evropi v letu 2020 (http://www.fao.org/plant-health-2020/en/). V ta namen so pripravili tudi raznolik in številen promocijski material, pri čemer bodo sodelovale tudi posamične članice Evropske unije s svojim inovativnim pristopom. Med drugim bosta Mednarodnemu letu zdravja rastlin 2020 posvečen kovanec za 2 EUR, poštna znamka in še mnogo drugega. Predstavnik Evropske agencije za varnost hrane (European Food Safety Authority, EFSA, http://www. efsa.europa.eu/) Guiseppe Strancanelli je predstavil pomen aktivnosti EFSA za EU pri soočanju z novimi izzivi na področju zdravja rastlin. Orisal je postopek izdelave ocene tveganja za škodljive organizme rastlin (Horizon Scanning, Pest Risk Analisis) in nov pripomoček za izvajanje programov preiskav, t.i. Pest Survey Cards. Sklop predavanj vabljenih predavateljev je zaključil predstavnik hrvaškega ministrstva za kmetijstvo Ivica Delić s predstavitvijo o vključevanju nove evropske zakonodaje na področju zdravja rastlin $v$ hrvaško zakonodajo, o spremembah na področju rastlinskega reprodukcijskega mate- riala, uporabe pesticidov, ter o izpolnjevanju zahtev Evropskega zelenega dogovora (European Green Deal, https://ec.europa.eu/info/strategy/priorities-2019-2024/european-green-deal en), zlasti njenega ključnega dela, t.i. Strategije »Od vil do vilic« (Farm to Fork Strategy, https://ec.europa.eu/food/farm2fork_en) za zagotavljanje zdrave hrane.

\section{Izzivi gozdarstva na Balkanu}

V sekciji za gozdarstvo so sodelovali predavatelji iz Hrvaške (Univerza v Zagrebu, Hrvaški gozdarski inštitut, podjetje Hrvatske Šume, Hrvaška agencija za poljedelstvo in hrano), Bosne in Hercegovine (Univerza v Sarajevu, Fakulteta za gozdarstvo) in Slovenije (Gozdarski inštitut Slovenije, Zavod za gozdove Slovenije).

Predstavljena je bila problematika invazivnih tujerodnih vrst $\mathrm{v}$ gozdarstvu globalno in na Hrvaškem. V sklopu predavanja so bili navedeni primeri vrst, ki na Hrvaškem predstavljajo velik problem (hrastova čipkarka (Corythucha arcuata), jesenov ožig (Hymenoscyphus fraxineus), veliki pajesen (Ailanthus altissima)). Omenjene so bile vrste, ki predstavljajo največjo grožnjo za to območje v prihodnosti (kitajski kozliček (Anoplophora chinensis), jesenov krasnik (Agrilus planipennis), borova ogorčica (Bursaphelenchus xylophilus), borov smolasti rak (Fusarium circinatum) in druge). Predstavili so tudi možnosti uporabe invazivnih tujerodnih vrst, na primer pridobivanje herbicidov iz velikega pajesena. Prav tako so predstavili načrte za raziskovanje načinov, kako zatreti hrastovo čipkarko.

V hrvaških gozdovih je trenutno eden najbolj perečih problemov hrastova čipkarka, ki z izsesavanjem hrastovih listov povzroča sušenje listov in domnevno prispeva $\mathrm{k}$ njihovemu hiranju. Vrsta naglo širi svoj areal na Balkanu, škoda zaradi te stenice pa se ne pojavlja samo na hrastih, ampak tudi na gabru, leski in kostanju.

Organizem, ki predstavlja potencialno največjo grožnjo za gozdove ne samo na Hrvaškem, ampak tudi drugod po Evropi, je kitajski kozliček. Gre za karantenskega škodljivca, ki je bil v preteklosti na Hrvaškem že najden. V vseh primerih so izvajali predpisane ukrepe za izkoreninjenje. V 2019 se je kitajski kozliček pojavil v Rugvici v nasadu ameriške borovnice (Vaccinium corymbosum), ki je nov gostitelj za to vrsto. Izvedeno je bilo obveščanje Evropske komisije in uničenje vseh rastlin ter intenziven monitoring na prizadetem območju. Pri tem je bila izpostavljena problematika nadzora uvoza rastlin $\mathrm{v}$ državo.

Predstavnik hrvaškega gozdarskega inštituta je predstavil izvajanje programov preiskav za škodljive organizme rastlin v gozdarstvu. Nakazal je možnost uporabe drona pri iskanju potencialnih simptomatičnih dreves na neprehodnem terenu in možnost uporabe avtomatiziranih pasti za potrebe optimizacije in povečanja učinkovitosti izvajanja programov preiskav v prihodnosti.

$\mathrm{Na}$ Hrvaškem je zelo pomembna proizvodnja želoda za vzgojo kvalitetnih sadik hrasta. Trenutno preizkušajo novo metodo za pripravo želoda na skladiščenje, t.j. termotera- 
pijo, ki naj bi nadomestila klasično tretiranje semena s pesticidi. Metoda se kaže kot obetavna za preprečevanje razvoja žuželk in nekaterih gliv v hrastovih semenih. Pri tem pa so opazili, da bo potrebno ogromno truda nameniti tudi samemu načinu shranjevanja semen.

Predstavljeni so bili biotični dejavniki, ki ovirajo pridelavo gozdnega reprodukcijskega materiala, t.j. škodljivci in bolezni listavcev in iglavcev v drevesnicah. Na Hrvaškem je proizvodnja gozdnega reprodukcijskega materiala zelo velika. Velik problem $v$ zadnjih letih predstavlja zmanjševanje števila sredstev za zaščito rastlin, dovoljenih za uporabo v drevesničarstvu, zato se Hrvati soočajo z izzivom uvajanja novih tehnologij in mehanizacije za pridelavo kvalitetnih sadik gozdnega drevja. Izpostavljeno je bilo tveganje pri uporabi pesticidov v gozdarstvu in poskusi hrvaške $\mathrm{z}$ uporabo ekoloških preparatov (npr. Neemovo olje, VitiSan, AQ-10, pripravek iz sahalinskega dresnika) za zatiranje hrastove pepelovke. Rezultati so zadovoljivi, vendar je potrebno raziskati tudi njihov vpliv na samo rast mladih dreves.

Kot vsako leto, je bilo tudi letos predstavljeno povečanje populacije malih glodavcev $\mathrm{v}$ državnih gozdovih na Hrvaškem. Mali glodalci so na Hrvaškem velik problem, saj v gozdovih povzročajo škodo z obžiranjem korenin, obžiranjem semen in prenašanjem bolezni (zoonoze).

Na hrvaškem spremljajo stanje gozdov ne samo v proizvodnih gozdovih, ampak tudi v gozdovih na zavarovanih območjih. Tako so bile na primer predstavljene glive, ki so bile najdene na odmrlih vejah bukve v naravnem parku Papuk. Ocenjujejo, da je prisotnost najdenih gliv (paraziti, saprofiti, endofiti) nizke intenzitete in najdene vrste trenutno niso problematične z vidika varstva gozda. Na primeru gozdnega parka Jasovac pa je bilo izpostavljena nujnost spremljanje zdravstvenega stanja drevja in spremljanje populacij škodljivih organizmov za ohranjanje zdravstvenega stanja gozdnega drevja. Predstavljena nam je bila tudi problematika gozdnega parka Jasikovac pri Gospiću, kjer je toča premera kokošjega jajca naredila ogromno škode na drevju. Trenutno se drevesa lepo obnavljajo, vendar je močno prisoten strah pred napadom podlubnikov.
Z novo evropsko zakonodajo na področju zdravja rastlin se je pojavila zahteva po vzpostavitvi nacionalnih referenčnih laboratorijev. Tako kot Laboratorij za varstvo gozdov Gozdarskega inštituta Slovenije, tudi Hrvaški gozdarski inštitut sodeluje $\mathrm{z}$ referenčnimi laboratoriji Evropske unije (EU Reference Laboratory, EURL).

Predavatelj iz Bosne in Hercegovine je predstavil spekter dejavnikov, ki negativno vplivajo na zdravstveno stanje gozdov $\mathbf{v}$ Bosni in Hercegovini. Tako kot $\mathbf{v}$ Sloveniji so tudi pri njih podlubniki na iglavcih najpomembnejši škodljivci, ki terjajo več desetmilijonske stroške zaradi gospodarskih izgub in obnove.

Kot vsako leto, smo se seminarja udeležili tudi Slovenci. Predstavili smo raziskavo ulova osmerozobega smrekovega lubadarja (Ips typographus) v pasti s feromonskimi vabami za to vrsto različnih proizvajalcev (Gozdarski inštitut Slovenije) in aktivnosti za omejevanje širjenja rjavenja borovih iglic ( $L e$ canosticta acicola) v Posočju (Zavod za gozdove Slovenije skupaj z Gozdarskim inštitutom Slovenije).

Predavanjem v dveh sekcijah v dopoldanskem delu so sledile strokovne razprave $\mathrm{v}$ popoldanskem delu, ki so obravnavale aktualne teme, med drugim problematiko ponarejanja pesticidov in omejitve gospodarjenja $\mathrm{z}$ gozdovi $\mathrm{v}$ zavarovanih in Natura 2000 območjih.

\section{Zaključek}

Razvoj gozdarstva gre $\mathrm{v}$ smeri integralnega varstva pred škodljivimi organizmi (Integrated Pest Management, IPM), zato bodo potrebne nove raziskave in uvajanje novih, inovativnih tehnologij. Hrvati izpostavljajo nezadostno financiranje raziskav na področju gozdarstva, kar je problem tudi v Sloveniji, zato nas vse nedvomno čaka še precej izzivov. Predvsem postaja problematika invazivnih vrst in predvsem karantenskih vrst vse bolj pereč problem, pri čemer nam vzporedne klimatske spremembe ne prinašajo nič dobrega. Ravno zaradi omenjenih problematik je informiranje in ozaveščanje širše javnosti, eden od ključnih načinov, kako preprečiti negativne posledice in omiliti že nastale.

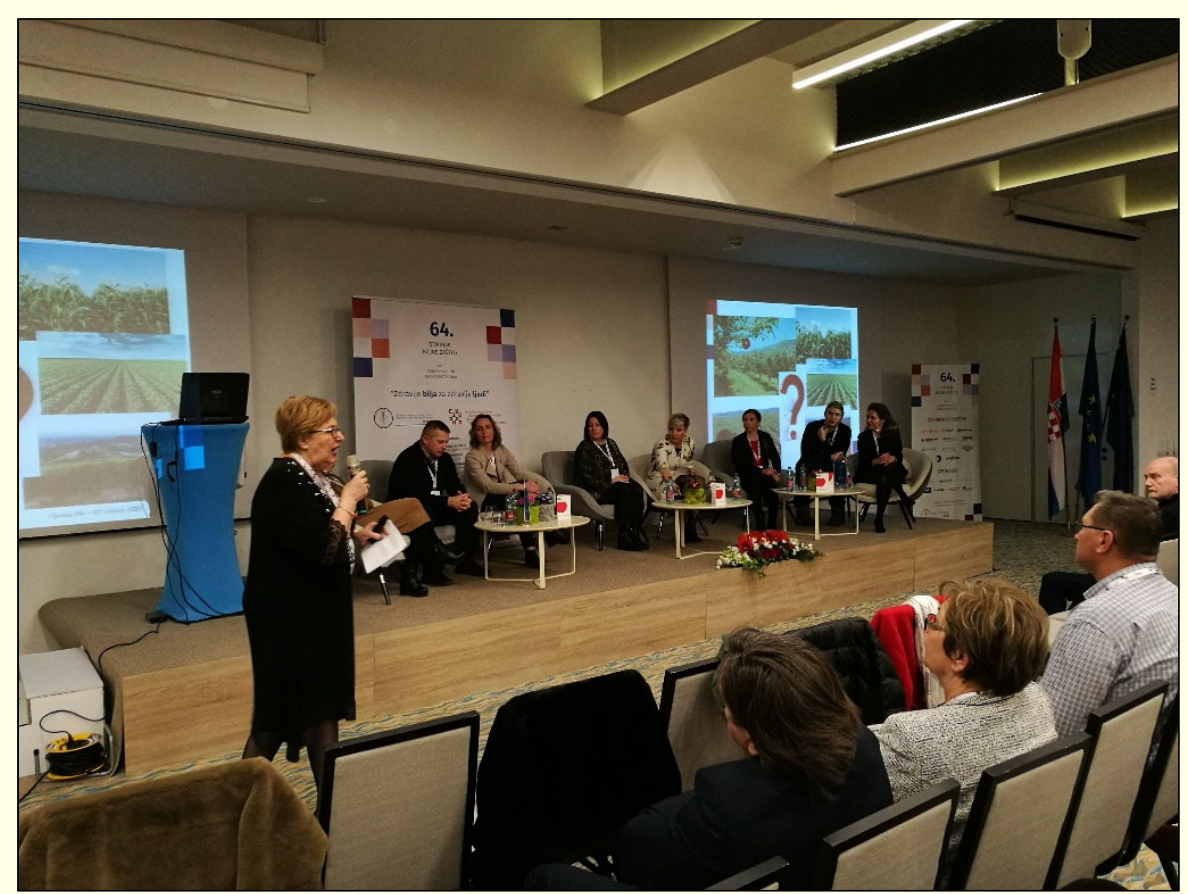

Slika 1: Utrinek s strokovne razprave. 